Research Article

\title{
Immunologic Response of HIV-Infected Children to Different Regimens of Antiretroviral Therapy: A Retrospective Observational Study
}

\author{
Teshale Ayele Mega, ${ }^{1}$ Firehiwot Belayneh Usamo, ${ }^{2}$ and Getandale Zeleke Negera ${ }^{1}{ }^{1}$ \\ ${ }^{1}$ Department of Clinical Pharmacy, School of Pharmacy, Institute of Health, Jimma University, Jimma, Ethiopia \\ ${ }^{2}$ Department of Pharmacy, College of Medicine and Health Science, Dilla University, Dila, Ethiopia \\ Correspondence should be addressed to Getandale Zeleke Negera; getandale@gmail.com
}

Received 27 December 2019; Revised 5 June 2020; Accepted 31 July 2020; Published 13 August 2020

Academic Editor: David Katzenstein

Copyright (c) 2020 Teshale Ayele Mega et al. This is an open access article distributed under the Creative Commons Attribution License, which permits unrestricted use, distribution, and reproduction in any medium, provided the original work is properly cited.

\begin{abstract}
Background. Both abacavir- (ABC-) based and zidovudine- (AZT-) based regimens are widely utilized for managing HIV infection in children. Unfortunately, there is a lack of data regarding their immunological response and associated risk factors in Ethiopia. Methods. A retrospective hospital-based cohort study was conducted on HIV-infected children in Jimma Medical Center (JMC). A total of 179 records were reviewed by including data from November 2015 to April 2017. Data were collected on sociodemographic, clinical characteristics of patients and drug-related variables. Data analysis was done using STATA 13.1. Mixedeffect linear regression was performed to assess the difference in CD4+ changes between groups adjusting for baseline characteristics. The change in predicted CD 4 count attributed to each regimen was also assessed by marginal analysis. $P<0.05$ for slope of the random-effect linear regression was used as an indicator for the presence of association. Result. Of 179 patients, 98 (54.7\%) were females. The mean $( \pm S D)$ duration of follow-up was $939.8 \pm 478.3$ and $984.92 \pm 453.1$ days for ABC and AZT groups, respectively. AZT group had a significant $C D 4+$ count gain per visit compared with their $A B C$ counterparts $((\beta=20.51,95 \%$ CI [6.37-34.65]), $P=0.004)$ over time. The regimen AZT + 3TC + LPV/r tended to have an excellent predicted CD4+ lymphocyte count change relative to all other regimens, while $\mathrm{ABC}+3 \mathrm{TC}+\mathrm{LPV} / \mathrm{r}$ had the least immunologic recovery (margins 338.0 cells/ $\mathrm{mm}^{3}$ versus 249.13 cells $/ \mathrm{mm}^{3}(P<0.001)$ ). Baseline CD4+ lymphocyte count, ART group, WHO clinical stages, and viral load were independent predictors for $\mathrm{CD} 4+$ change overtime. Conclusion. AZT-based regimens seem to have better immunological response compared to $\mathrm{ABC}$-based regimens. Immunologic response was described worse in patients with a viral load of $>1000$ copies/ml, low baseline CD4+ count, advanced WHO clinical stages, and ABC-containing regimens. Further study is needed to clarify these aspects.
\end{abstract}

\section{Background}

Currently, 1.7 million children are living with human immunodeficiency virus (HIV) and over $90 \%$ of them live in sub-Saharan Africa $[1,2]$. Ethiopia has the largest population of HIV-infected children in the region. According to an estimate by the Federal HIV/AIDS Prevention and Control Office (FHAPCO), there are over 738,976 people living with HIV/AIDS in Ethiopia [3]. Of these, 178,500 are children younger than 15 years of age [4].
The initiation of potent antiretroviral therapy (ART) in the mid-1990s has dramatically reduced HIV-associated morbidity and mortality [5-8]. Antiretroviral therapy reduces HIV-associated morbidity and mortality by suppressing HIV replication to undetectable levels and providing a consistent increase in the number of CD4+ T lymphocytes $[9,10]$. The resulting effect is the recovery of the immune system, and thus, immune reconstitution is an important outcome measure of ART [11]. According to the recent report, 59\% of children living with HIV were on treatment in Ethiopia [12]. 
The earlier World Health Organization (WHO) guidelines recommended using a nucleoside reverse transcriptase inhibitor (NRTI) backbone including a thymidine analogue stavudine $(\mathrm{d} 4 \mathrm{~T})$ or zidovudine (AZT) together with lamivudine (3TC) for paediatric HIV treatment [13]. But in 2010, the WHO guideline discouraged the use of $\mathrm{d} 4 \mathrm{~T}$ because of high lipodystrophy rates in adults and adolescents [14]. As a result, the current guidelines were changed to recommend substitution of the thymidine analogue with abacavir $(\mathrm{ABC})$ depending on studies which reported fewer side effects and improved virological responses with $\mathrm{ABC}$ compared to d4T or AZT $[15,16]$.

In Ethiopia, the initial ART regimen included the use of $\mathrm{d} 4 \mathrm{~T}$ as a preferred first-line NRTI for paediatric HIV treatment. In 2012, Ethiopia implemented the d4T phase-out program, and $\mathrm{ABC}$ became routinely used as a standard of care [17]. Currently, both ABC- and AZT-based regimens are routinely utilized. However, there is a lack of study regarding the immunological response of $\mathrm{ABC}$ - and $\mathrm{AZT}$ containing regimens among $\mathrm{HIV}$-infected children in Ethiopia. Studies conducted in some African children [18-21] showed an encouraging and comparable immunologic response to those obtained among children in wellresourced countries $[11,22,23]$. In this study, we compared the immunological response and associated factors in a cohort of HIV-infected children receiving ABC- and AZTcontaining regimens.

\section{Methods}

2.1. Study Design and Setting. A retrospective hospital-based cohort study was conducted on HIV-infected children in Jimma Medical Center (JMC). JMC is located in Jimma town, $355 \mathrm{~km}$ from Addis Ababa. It is currently the only teaching and specialized hospital in the Southwest region of Ethiopia. The hospital serves as a referral site and provides specialized care for Southwest Ethiopia with a catchment population of about 15 million. The study was conducted from April 10 to May 10, 2017, by including data from November 2015 to April 2017.

2.2. Study Population and Variables. We included HIV-infected children ( $<15$ years) who were on ABC- and AZTbased regimens that fulfill the eligibility criteria. Patients on ABC- and AZT-based first-line regimens, having at least six months of follow-up with good adherence, whose records were legible and complete, who have CD4 count at least at the baseline and six months, and younger than 15 years were included in the study. Those transferred out within $<6$ months of follow-up and patients with incomplete records were excluded. The study was conducted by dividing the total sample into two major classes as ABC group and AZT group.

Data were collected on sociodemographic characteristics (age, sex, area of residence, weight $(\mathrm{kg})$, height $(\mathrm{cm})$, and body mass index (BMI)), HIV-related factors (CD4 count and WHO clinical stage), treatment-related factors (types of ART regimen, opportunistic infection (OI) prophylaxis (cotrimoxazole preventive therapy (CPT) and isoniazid preventive therapy (IPT)), and antitubercular treatment), and immunological response (CD4+change).

2.3. Sample Size Determination. The number of patients who fulfilled the eligibility criteria for the ABC group was 87 and all of them were included. From those on AZT-based regimen, 92 eligible patients were included, making ABC-toAZT group ratio of $1: 1.05$. Finally, a total of 179 subjects, with 87 charts of patients from the $\mathrm{ABC}$ group and 92 patients from the AZT group were reviewed.

2.4. Sampling Technique. Since the number of patients on $\mathrm{ABC}$-based regimen was limited, we included all eligible patients. A simple random sampling technique was used to select 92 patient charts for AZT-based regimens using a computer-generated random number.

\subsection{Data Collection Procedure and Quality Assurance.} Data on socio-demographic, clinical, laboratory, and drugs administered were collected by record review using English version checklists. The data collection tool was carefully prepared after reviewing relevant literature studies to enable the data collectors to gather all the information required to address the study objectives. A 2-day training was provided on the data collection tool and general procedures for data collectors, i.e., 2 pharmacists (B. Pharm) and 2 nurses. Data from antiretroviral drugs and patient information sheet were collected by pharmacists, and data from ART clinic intake form, HIV care/ART follow-up, and patient sheet were collected by the nurses. The baseline body mass index of the subjects was later calculated after collection of baseline height and weight of the patient from the patient chart. Pretest was conducted on $5 \%$ of the eligible records.

\subsection{Operational Definition of Terms}

Good adherence: estimated adherence level of $>95 \%$ [24] as recorded by ART physicians/nurses

Child: age $<15$ years [25]

Lost to follow-up: refer to a patient who has missed clinical or drug pickup appointments permanently [26].

2.7. Ethical Consideration. The study was approved by the Institutional Review Board (IRB) of Jimma University. It has designated with an IRB number of IHRPGB/112/2017. The need for informed consent was waived because of the retrospective, anonymous nature of the study. During data collection, confidentiality was ensured, and for this reason, the name and address of the patient were not recorded in the data collection checklist.

2.8. Statistical Analysis. Data were double-entered into EpiData and exported to STATA 13.1 for cleaning and analysis. Descriptive analysis was performed, and results were 
presented in text, tables, and charts. Bivariate and multivariate mixed-effects linear regressions for repeated measurements were performed to assess the adjusted effect of the ART regimen and identify additional predictors of CD4+ recovery. The coefficient of mean CD4+ count with 95\% confidence intervals was used as a measure of the strength of association, and $P<0.05$ was considered to declare a statistical significance. Marginal analysis was also conducted to see the difference among the specific regimen category.

\section{Results}

3.1. Overview of the Study Participants. During the study period, a total of 367 patients started antiretroviral therapy (ART) and were treated for at least 6 months. Of these, 108 from $\mathrm{ABC}$ group and 212 from AZT group have a complete CD4+ count at the $6^{\text {th }}$ month of treatment. Thirty-two patients were excluded initially from either regimen due to missed CD4+ count at 6 months and 30 (21 and 9 from ABC and AZT, respectively) because of the adherence problem, and 179 patients were included in the analysis (Figure 1).

The mean \pm standard deviation (SD) duration of followup was $939.8+478.3$ and $984.92+453.1$ days for the $A B C$ and AZT groups, respectively. During the study period, a total of 4 patients (1 (1.14\%) patient from the ABC group and 3 (3.3\%) from the AZT group; $P=0.339$ ) died.

\subsection{Baseline Socio-Demographic and Clinical Characteristics.} We included 179 patients, of whom 98 (54.75) were females. One hundred forty $(78.2 \%)$ of the patients had a BMI of less than fifth centile, and there was a statistically significant difference between groups $(P=0.03)$. Baseline socio-demographic and clinical characteristics of the study participants are depicted in Table 1.

3.3. Immunological Response. The overall change in the mean standard deviation $( \pm \mathrm{SD})$ of $\mathrm{CD} 4+$ lymphocyte count was $139.3( \pm 55.7)$ cells $/ \mathrm{mm}^{3}$ for the ABC group and 150.5 $( \pm 42.1)$ cells $/ \mathrm{mm}^{3}$ for the AZT group. The mean change in CD4+ lymphocyte count from baseline for the past 18 months was presented comparatively in Figure 2. The SDs are 55.3 vs. $41.6,66.3$ vs. 63.1 , and 87.7 vs. 65.1 at $6^{\text {th }}, 12^{\text {th }}$, and $18^{\text {th }}$ months for ABC- and AZT-based regimens, respectively.

As shown in the figure, the CD4+ lymphocyte count trajectory belonging to AZT-based regimen looks steeper after the first 6 months of therapy.

Patients on AZT + 3TC + NVP had the highest baseline CD4+ lymphocyte count, followed by AZT $+3 \mathrm{TC}+\mathrm{LPV} / \mathrm{r}$ and $\mathrm{ABC}+3 \mathrm{TC}+\mathrm{NVP}$. The lowest baseline CD4+ count was recorded for $\mathrm{ABC}+3 \mathrm{TC}+\mathrm{LPV} / \mathrm{r}$ (Table 2).

3.4. Predictors of CD4+ Lymphocyte Count Change. We conducted a mixed-effect linear regression using a consecutive CD4+ lymphocyte count measured over the past 18 months as an outcome variable. The slope of random-effect linear regression was used to report the overtime change in CD4+ count attributed to the predictor variables. The overall average gain in CD4+ count every six months was 53.0 cells $/ \mathrm{mm}^{3}(P<0.001$ and 95\% CI [46.86-59.20]) with an interclass correlation coefficient of $65.5 \%(P<0.001)$. This implies a significant proportion of variability in CD4+ lymphocyte count change due to patient-specific factors. Among the groups, $36.73 \%$ of the variation in $\mathrm{CD} 4+$ lymphocyte change variability was explained by differences in ART regimens $(P<0.001)$.

Body mass index, weight for height, ART group, baseline, CD4+ lymphocyte count, occurrence of opportunistic infections (OIs), WHO clinical staging, viral load, nutritional status, and exposure to antitubercular drugs were associated with CD4+ lymphocyte count change on binary linear regression. After adjusting for all confounders, ART group, baseline CD4+ lymphocyte count, WHO clinical stages, and viral load remained independent predictors for $\mathrm{CD} 4+$ lymphocyte count change.

Therefore, patients who commenced on AZT-based regimens had a significant change in CD4+ lymphocyte count at each visit. Accordingly, patients exposed to AZTbased regimens had 20.51 cells $/ \mathrm{mm}^{3} \mathrm{CD} 4+$ count advantage every six months ( $\beta=20.51,95 \%$ CI [6.37-34.65]). Each unit increment in baseline CD4+ count will contribute to 0.55 cells $/ \mathrm{mm}^{3} \mathrm{CD} 4$ gain every half year $(\beta=0.55,95 \% \mathrm{CI}$ [0.49-0.69]).

On the contrary, patients with WHO stages III and IV were in a precarious situation in terms of their $\mathrm{CD} 4+$ count recovery. Every six months, patients with WHO stage III and WHO stage IV had 47.61 and $73.54 \mathrm{CD} 4+$ lymphocyte count disadvantages, respectively $(\beta=-47.61[-84.27-(-10.96)]$ and $\beta=-73.54$ $[-118.27-(-28.81)])$. In addition, patients with a viral load of $>1000$ copies/ml had $28 \mathrm{CD} 4+$ lymphocyte count disadvantages every half year $(\beta=-27.68[-47.75-(-7.61)])$ (Table 3$)$.

3.5. Postestimation Treatment Effects. We also conducted a marginal analysis to predict the changes in the mean CD4+ lymphocyte counts associated with each regime and to identify the regimen with the lowest performance. Therefore, except $A B C+3 T C+N V P$, the other two $A B C$-based regimens, namely, $\mathrm{ABC}+3 \mathrm{TC}+\mathrm{EFV}$ and $\mathrm{ABC}+3 \mathrm{TC}+\mathrm{LPV} / \mathrm{r}$, deemed to be the lowest performing regimens as compared to their AZT counterparts. Accordingly, the predicted mean CD4+ count for paediatrics treated with AZT + 3TC + NVP had 318.3 cells $/ \mathrm{mm}^{3}$ of CD4+ lymphocyte count change, and it was 296.33 cells $/ \mathrm{mm}^{3} \mathrm{CD} 4+$ for those treated with $\mathrm{ABC}+3 \mathrm{TC}+\mathrm{EFV}$. The change is statistically significant in either case $(P<0.001)$. The regimen $\mathrm{AZT}+3 \mathrm{TC}+\mathrm{LPV} / \mathrm{r}$ tended to have an excellent predicted $\mathrm{CD} 4+$ lymphocyte count change relative to all other regimens, while $\mathrm{ABC}+3 \mathrm{TC}+\mathrm{LPV} / \mathrm{r}$ performed the opposite (margins 338.0 cells $/ \mathrm{mm}^{3} \quad$ versus 249.13 cells $\left./ \mathrm{mm}^{3} \quad(P<0.001)\right)$ (Table 4).

\section{Discussion}

This study was the first ever to compare the immunological response of ABC- and AZT-based regimens among HIVinfected children in Ethiopia. The biannual analysis of mean 


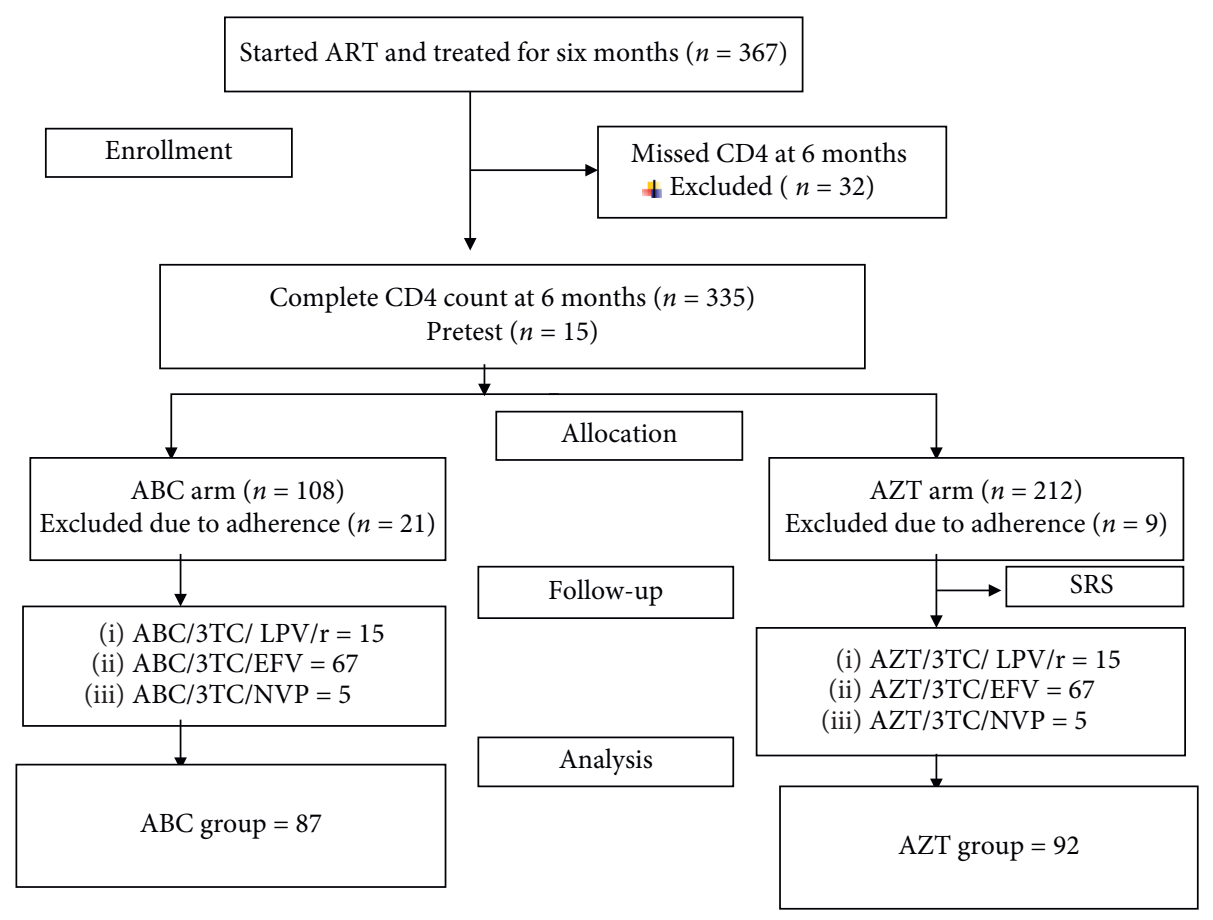

FIGURE 1: Sample recruitment chart of patients attending ART clinic, in JMC, from April 10 to May 10, 2017. SRS: simple random sampling.

TABLe 1: Comparative baseline characteristics of the cohort at JMC, from April 10 to May 10, 2017.

\begin{tabular}{|c|c|c|c|c|}
\hline $\begin{array}{l}\text { All } n=179 \\
\text { Variables }\end{array}$ & & $\mathrm{ABC}$ group $(n=87)$ & AZT group $(n=92)$ & $P$ value \\
\hline Sex & $\begin{array}{c}\text { Male } \\
\text { Female }\end{array}$ & $\begin{array}{l}42(48.3 \%) \\
45(51.7 \%)\end{array}$ & $\begin{array}{l}39(42.4 \%) \\
53(57.6 \%)\end{array}$ & 0.42 \\
\hline Age (years) & $\begin{array}{l}<3 \text { years } \\
3-5 \text { years } \\
>5 \text { years }\end{array}$ & $\begin{array}{l}11(12.6 \%) \\
18(20.7 \%) \\
58(66.7 \%) \\
\end{array}$ & $\begin{array}{l}12(13.0 \%) \\
20(21.7 \%) \\
60(65.2 \%) \\
\end{array}$ & 0.97 \\
\hline BMI (baseline) & $\begin{array}{l}<5^{\text {th }} \text { centile } \\
>5^{\text {th }} \text { centile }\end{array}$ & $\begin{array}{l}74(85.0 \%) \\
13(14.9 \%) \\
\end{array}$ & $\begin{array}{l}66(71.7 \%) \\
26(28.3 \%) \\
\end{array}$ & 0.03 \\
\hline Maternal HIV status & $\begin{array}{c}\text { Positive } \\
\text { Unknown }\end{array}$ & $\begin{array}{c}78(89.7 \%) \\
9(10.3 \%) \\
\end{array}$ & $\begin{array}{c}83(90.2 \%) \\
9(9.8 \%) \\
\end{array}$ & 0.91 \\
\hline Area of residence & $\begin{array}{l}\text { Urban } \\
\text { Rural }\end{array}$ & $\begin{array}{l}66(75.9 \%) \\
21(24.1 \%) \\
\end{array}$ & $\begin{array}{l}68(73.9 \%) \\
24(26.1 \%) \\
\end{array}$ & 0.76 \\
\hline Baseline CD4+ (mean +SD) & $166.31+76.223$ & $178.78+71.12$ & 0.26 & \\
\hline WHO stage & $\begin{array}{l}\text { I } \\
\text { II } \\
\text { III } \\
\text { IV } \\
\end{array}$ & $\begin{aligned} & 8(9.2 \%) \\
& 24(27.6 \%) \\
& 45(51.7 \%) \\
& 10(11.5 \%) \\
&\end{aligned}$ & $\begin{aligned} & 3(3.3 \%) \\
& 40(43.5 \%) \\
& 42(45.7 \%) \\
& 7(7.6 \%) \\
&\end{aligned}$ & 0.08 \\
\hline Functional status & $\begin{array}{c}\text { W/A } \\
\mathrm{A} / \mathrm{D} \\
\mathrm{B} / \mathrm{r}\end{array}$ & $\begin{aligned} & 72(82.8 \%) \\
& 12(13.8 \%) \\
& 3(3.4 \%) \\
&\end{aligned}$ & $\begin{array}{c}88(95.7 \%) \\
0 \\
4(4.3 \%) \\
\end{array}$ & 0.001 \\
\hline TB (treatment) & $\begin{array}{l}\text { Yes } \\
\text { No }\end{array}$ & $\begin{array}{c}3(3.4 \%) \\
84(96.6 \%) \\
\end{array}$ & $\begin{array}{c}9(9.8 \%) \\
83(90.2 \%) \\
\end{array}$ & 0.06 \\
\hline OI prophylaxis & $\begin{array}{c}\text { Both CPT and INH } \\
\text { CPT only } \\
\text { Neither }\end{array}$ & $\begin{aligned} 85 & (97.7 \%) \\
1 & (1.1 \%) \\
1 & (1.1 \%)\end{aligned}$ & $\begin{aligned} 89 & (96.7 \%) \\
1 & (1.1 \%) \\
2 & (2.2 \%)\end{aligned}$ & 0.69 \\
\hline Nutritional status & $\begin{array}{l}\text { Normal } \\
\text { SAM }\end{array}$ & $\begin{array}{l}45(51.7 \%) \\
42(48.3 \%)\end{array}$ & $\begin{array}{l}57(62.0 \%) \\
35(38.0 \%)\end{array}$ & 0.17 \\
\hline
\end{tabular}




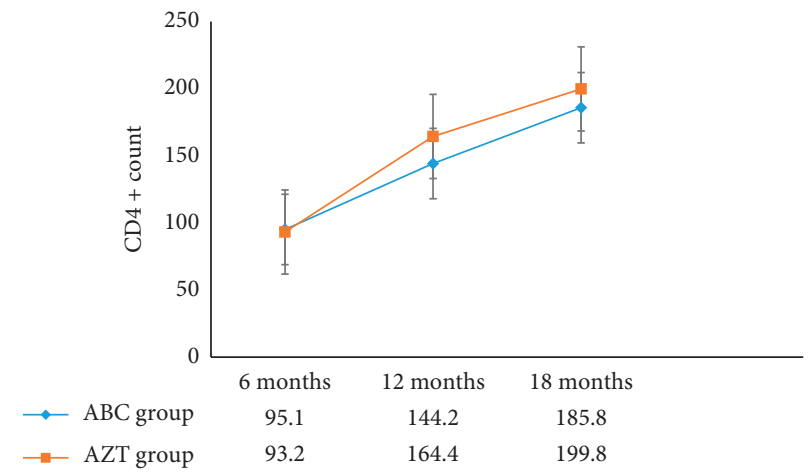

FIgure 2: Comparative mean CD4+ count gains for paediatric patients exposed to ABC versus AZT from April 10 to May $10,2017$.

TABLE 2: CD4+ lymphocyte count at different points of time with respect to each regimen.

\begin{tabular}{|c|c|c|c|c|}
\hline Regimen & At baseline & 6 months & 12 months & 18 months \\
\hline $\mathrm{ABC}+3 \mathrm{TC}+\mathrm{LPV} / \mathrm{r}$, mean $( \pm \mathrm{SD})$ & $133.0(8.01)$ & $94.4(14.18)$ & $165.7(21.9$ & $162.83(56.4)$ \\
\hline $\mathrm{ABC}+3 \mathrm{TC}+\mathrm{EFV}$ & $171.2(5.59)$ & $95.2(6.80)$ & $142.59(9.9)$ & $195.10(18.4)$ \\
\hline $\mathrm{AZT}+3 \mathrm{TC}+\mathrm{NVP}$ & $221.0(9.16)$ & $68.6(20.86)$ & $116.3(22.6)$ & $135.3(17.6)$ \\
\hline $\mathrm{AZT}+3 \mathrm{TC}+\mathrm{LPV} / \mathrm{r}$ & $191.67(10.83)$ & $91.2(10.2)$ & $161(14.4)$ & $217.6(11.0)$ \\
\hline $\mathrm{AZT}+3 \mathrm{TC}+\mathrm{EFV}$ & $174.2(4.88)$ & $95.1(4.98)$ & $165.4(8.4)$ & $197.3(10.2)$ \\
\hline $\mathrm{ABC}+3 \mathrm{TC}+\mathrm{NVP}$ & $186.8(11.95)$ & $99(22.58)$ & $145.8(25.1)$ & $208.2(31.1)$ \\
\hline
\end{tabular}

TABLE 3: Random-effect linear regression analysis of trend of CD4+ count (slope, cells $/ \mathrm{mm}^{3} / 6$ month) at JMC, from April 10 to May 10 , 2017.

\begin{tabular}{|c|c|c|c|c|c|c|}
\hline \multicolumn{2}{|c|}{ Variables } & \multirow{2}{*}{$\begin{array}{c}n(\%) \\
98(54.75)\end{array}$} & \multirow{2}{*}{$\begin{array}{c}\text { Unadjusted } \% \beta[95 \% \mathrm{CI}] \\
0\end{array}$} & \multirow[t]{2}{*}{$P$ value } & \multirow[t]{3}{*}{ Adjusted $\% \beta[95 \% \mathrm{CI}]$} & \multirow[t]{3}{*}{$P$ value } \\
\hline & Male & & & & & \\
\hline sex & Female & $81(45.25)$ & $7.46[-13.61-28.53]$ & 0.488 & & \\
\hline Age: median (IQR) & $7(4-9)$ & $179(100)$ & $-0.56[-4.24-3.12]$ & 0.765 & & \\
\hline \multirow{2}{*}{ BMI } & Below $5^{\text {th }}$ centile & $140(78.21)$ & $-19.45[-44.56-5.70]$ & 0.130 & $-5.18[-22.99-12.63]$ & 0.569 \\
\hline & Above $5^{\text {th }}$ centile & $39(21.79)$ & 0 & & 0 & \\
\hline \multirow{3}{*}{ Weight for height } & $\leq 70 \%$ & $36(20.11)$ & $-31.84[-57.96-(-5.72)]$ & 0.017 & $2.31[-18.10-22.72]$ & 0.825 \\
\hline & $70-85 \%$ & $14(7.82)$ & $-9.84[-48.62-28.94]$ & 0.619 & $5.91[-21.17-32.99]$ & 0.669 \\
\hline & $\geq 85 \%$ & $129(72.07)$ & 0 & & 0 & \\
\hline \multirow{2}{*}{ In care of the child } & Mother & $24(13.41)$ & $16.91[-13.74-47.57]$ & 0.280 & & \\
\hline & Others & $155(86.59)$ & 0 & & & \\
\hline \multirow{2}{*}{ Maternal status } & Dead & $33(18.44)$ & $-3.244[-30.53-24.06]$ & 0.816 & & \\
\hline & Live & $146(8156)$ & 0 & & & \\
\hline \multirow{2}{*}{ Maternal serostatus } & Unknown & $18(10.06)$ & $-5.01[-40.54-30.53]$ & 0.782 & & \\
\hline & Negative & $161(89.94)$ & 0 & & & \\
\hline \multirow{2}{*}{ Paternal status } & Dead & $47(26.26)$ & $0.32[-23.39-24.03]$ & 0.979 & & \\
\hline & Live & $132(73.74)$ & 0 & & & \\
\hline \multirow{2}{*}{ Residence } & Urban & $134(78.86)$ & 0 & & & \\
\hline & Rural & $45(25.14)$ & $-6.59[-31.04-17.87]$ & 0.598 & & \\
\hline \multirow{2}{*}{ ART group } & $\mathrm{ABC}$ & $87(48.60)$ & 0 & & 0 & \\
\hline & $\mathrm{AZT}$ & $92(51.40)$ & $30.42[9.89-50.94]$ & 0.004 & $20.51[6.37-34.65]$ & 0.004 \\
\hline CD4 count & $162(117-221)$ & $179(100)$ & $0.72[0.62-0.82]$ & $\leq 0.001$ & $0.55[0.49-0.69]$ & $\leq 0.001$ \\
\hline \multirow{2}{*}{ OI occurred } & No & 121 & 0 & & 0 & \\
\hline & Yes & 58 & $-49.12[-70.49-(-27.74)]$ & $\leq 0.001$ & $-18.65[-5.49-42.78]$ & 0.130 \\
\hline \multirow{2}{*}{ Viral load } & $\leq 1000$ copies $/ \mathrm{ml}$ & $146(83.43)$ & 0 & & & \\
\hline & $>1000$ copies $/ \mathrm{ml}$ & $29(16.57)$ & $-50.21[-77.71-(-22.71)]$ & $\leq 0.001$ & $-27.68[-47.75-(-7.61)]$ & 0.007 \\
\hline \multirow{4}{*}{ WHO stage } & Stage I & $11(6.15)$ & 0 & & 0 & \\
\hline & Stage II & $64(35.75)$ & $-31.43[-73.23-10.37]$ & 0.141 & $-28.63[-64.05-6.71]$ & 0.112 \\
\hline & Stage III & $87(48.60)$ & $-94.64[-136.08-(-53.19)]$ & $\leq 0.001$ & $-47.61[-84.27-(-10.96)]$ & 0.011 \\
\hline & Stage IV & $17(9.50)$ & $-151.41[-199.26-(-103.56)]$ & $\leq 0.001$ & $-73.54[-118.27-(-28.81)]$ & 0.001 \\
\hline \multirow{2}{*}{ Nutritional status } & Normal & $102(57.00)$ & 0 & & 0 & \\
\hline & SAM & $77(43.00)$ & $-38.79[-59.28-(-18.30)]$ & $\leq 0.001$ & $-13.42[-35.34-8.50]$ & 0.230 \\
\hline \multirow{2}{*}{ TB treatment } & No & $166(92.74)$ & 0 & & 0 & \\
\hline & Yes & $13(7.26)$ & $-61.14[-103.84-(-18.43)]$ & 0.005 & $-32.58[-65.18-0.21]$ & 0.050 \\
\hline
\end{tabular}


TABLE 4: The predicted CD4+ lymphocyte count change of paediatric patients receiving ABC- and AZT-based regimens at JMC.

\begin{tabular}{|c|c|c|c|c|c|}
\hline \multirow{2}{*}{ ART regimens } & \multicolumn{2}{|c|}{ Delta method } & \multirow{2}{*}{$t$} & \multirow{2}{*}{$P$ value } & \multirow{2}{*}{$95 \%$ CI } \\
\hline & Margins & Standard error & & & \\
\hline $\mathrm{AZT}+3 \mathrm{TC}+\mathrm{NVP}$ & 318.3 & 25.38 & 12.54 & $P<0.001$ & $268.38-368.17$ \\
\hline $\mathrm{AZT}+3 \mathrm{TC}+\mathrm{EFV}$ & 320.3 & 6.40 & 50.05 & $P<0.001$ & $307.73-332.89$ \\
\hline $\mathrm{AZT}+3 \mathrm{TC}+\mathrm{LPV} / \mathrm{r}$ & 338.0 & 14.23 & 23.76 & $P<0.001$ & $310.03-365.97$ \\
\hline $\mathrm{ABC}+3 \mathrm{TC}+\mathrm{NVP}$ & 337.8 & 21.73 & 15.54 & $P<0.001$ & 295.07380 .53 \\
\hline $\mathrm{ABC}+3 \mathrm{TC}+\mathrm{EFV}$ & 296.33 & 7.22 & 41.05 & $P<0.001$ & $282.14-310.52$ \\
\hline $\mathrm{ABC}+3 \mathrm{TC}+\mathrm{LPV} / \mathrm{r}$ & 249.13 & 15.12 & 16.48 & $P<0.001$ & 219.41-278.85 \\
\hline
\end{tabular}

CD4+ gain showed that the maximum gain in mean CD4+ count was attained with $\mathrm{AZT}+3 \mathrm{TC}+\mathrm{LPV} / \mathrm{r}$, while $\mathrm{ABC}+3 \mathrm{TC}+\mathrm{LPV} / \mathrm{r}$ had the least immunologic recovery over the entire treatment course. The CD4+ lymphocyte count trajectory showed a linear trend. Baseline CD4+ lymphocyte count, ART group, WHO clinical stages, and viral load were independent predictors for CD4+ changes over time.

Our finding of mean CD4+ recovery was inconsistent with a randomized open-label study by Mulenga et al. [27], where a comparable immunologic response was achieved between AZT- and ABC-containing regimens. A study by Cassim et al. [28] also failed to show a significant difference in terms of immunologic response between ART regimens. The higher CD4+ recovery with AZT-based regimens in this study might be due to a higher baseline CD4+ count of those patients who were on AZT-containing regimens (Table 1). In addition, the difference in the study design might contribute to the variation. This is thus an additional evidence to advocate to the test and treat strategy as opposed to waiting for dropping of CD4 counts at lower thresholds [24]. The finding from the marginal analysis also indicated that the change in mean CD4+ count is significantly higher in AZT-based regimens. Adult immunologic studies indicated that a linear trend in CD4+ increment at the early phase of therapy is expected and it became flat with minimal CD4+ gain later after $18^{\text {th }}$ month of treatment course [29]. However, the linear trend of immunologic recovery may indicate our study was ended prematurely.

The overall random-effect linear regression analysis had pointed out that baseline CD4+ lymphocyte count, ART group, WHO clinical stages, and viral load were independent predictors for $\mathrm{CD} 4+$ change overtime.

The marginal effects of each regimen confirmed that the immunologic outcome associated with $\mathrm{AZT}+3 \mathrm{TC}+\mathrm{LPV} / \mathrm{r}$ (margins $=338.0$ cells $/ \mathrm{mm} 3 /, P<0.001$ ) was the most favorable followed by ABC+3TC+NVP ( $m=337.8$ cells $/$ $\mathrm{mm} 3, \quad P<0.001)$ and $\mathrm{AZT}+3 \mathrm{TC}+\mathrm{EFV} \quad(m=320.3$, $P<0.001)$. However, $\mathrm{ABC}+3 \mathrm{TC}+\mathrm{LPV} / \mathrm{r}$ had the lowest predicted change in CD4+ count $(m=249.13, P<0.001)$, implying minimal immunologic response, and further study is needed to clarify this finding.

Patients who commenced on AZT-based regimens had greater CD4+ improvement over time. Accordingly, those patients who had exposed to AZT-based regimens were associated with an average CD4+ count advantage of 20.51 cells $/ \mathrm{mm}^{3} \quad(\beta=20.51,95 \%$ CI [6.37-34.65]). This finding is inconsistent with the Paediatric European Network for the Treatment of AIDS (PENTA 5) study, where children on ABC-based regimens had better immunologic response as compared to AZT-containing regimens [30]. This variation might be due to differences in study design (RCT vs. retrospective), study setup, and sample size.

In the cohort, baseline CD4+ count was another positive predictor for successful immunologic recovery. Therefore, each unit increment in the baseline CD4+ count will contribute to 0.55 cells $/ \mathrm{mm}^{3} \mathrm{CD} 4$ gain every half year $(\beta=0.55,95 \% \mathrm{CI}$ [0.49-0.69]). This is concurrent with previous studies [31-34], in which a higher baseline CD4+ lymphocyte count was associated with better immunologic response. This could be due to less extensively depleted immune system, which will be boosted easily after initiation of ART. It is also in agreement with the current WHO ART guidelines [35], which recommends the initiation of ART at diagnosis (test and treat) regardless of CD4+ count and WHO stage.

On the contrary, patients with WHO stages III and IV were in a precarious situation in terms of their CD4+ count recovery. Every six months, patients with WHO stage III and WHO stage IV had 47.61 and 73.54 CD4+ lymphocyte count disadvantage, respectively $(\beta=-47.61[-84.27-(-10.96)]$ and $\beta=-73.54$ $[-118.27-(-28.81)])$. This is in agreement with studies conducted in Nigeria [36] and Tanzania [37], in which advanced clinical stage was associated with worse CD4+ recovery. Similar observation was also reported by Kaufmann et al. [38], in which patients with advanced HIV stage had poor immune recovery compared to those in the early stage of the disease. This finding suggests that patients with advanced HIV/AIDS and profound immune suppression need special attention to improve their outcome. Similarly, patients with a viral load of $>1000$ copies/ $\mathrm{ml}$ had a worse immunologic response $(\beta=-27.68[-47.75-$ $(-7.61)])$. This finding is consistent with the study conducted by Zhou et al. [39].

This study had several possible limitations. Firstly, because of the retrospective nature of the study, we were not able to capture some important data such as adverse drug effects of ART. Second, as the sample size was relatively small, the power to detect definitive differences may have been limited. It was a single-site hospital-based study, and therefore, the findings may not be generalizable to the general population, and measures of adherence by health professionals that may not fit the reality are some of the limitations.

\section{Conclusion}

In the current study, patients with $\mathrm{AZT}+3 \mathrm{TC}+\mathrm{LPV} / \mathrm{r}$ had a better immunologic recovery. Immunologic response was described worse in patients with a viral load of $>1000$ copies/ 
$\mathrm{ml}$, low baseline CD4+ count, advanced WHO clinical stages, and ABC-containing regimens. Further study is needed to clarify these aspects.

\section{Abbreviations}

ART: Antiretroviral therapy

CD4+: Cluster of differentiation 4

CI: Confidence interval

CPT: Cotrimoxazole preventive therapy

HIV: Human immunodeficiency virus

JMC: Jimma Medical Center

SD: $\quad$ Standard deviation.

\section{Data Availability}

The data used to support the findings of this study are available from the corresponding author on request.

\section{Ethical Approval}

The study was approved by the Institutional Review Board (IRB) of the Institute of Health Sciences, Jimma University. The need for informed consent was waived because of the retrospective, anonymous nature of the study.

\section{Conflicts of Interest}

The authors of this paper have no competing interests.

\section{Authors' Contributions}

TA conceived the study, collected and analysed the data, and drafted the manuscript. FB conceived the study and collected and analysed the data. GZ conceived the study, analysed the data, and reviewed the manuscript. All authors have read and approved the manuscript.

\section{Acknowledgments}

The authors thank the study participants, data collectors, and all staff members of Jimma Medical Center for their kind cooperation in conducting this thesis. The authors also would like to thank Jimma University for allowing us to conduct this research.

\section{References}

[1] Joint United Nations Programme on HIV/AIDS (UNAIDS), "Report on the global aids epidemic," vol. 1-6, UNAIDS, Geneva, Switzerland, 2019http://www.unaids.org/en/resources/fact-sheet.

[2] UNAIDS, “The Gap Report, 2014," 2019, http://www.unaids.org/ sites/default/files/en/media/unaids/contentassets/documents/ unaidspublication/2014/UNAIDS_Gap_report_en.pdf.

[3] G. Z. Negera and T. A. Mega, "Clinical outcome of admitted HIV/AIDS patients in Ethiopian tertiary care settings: a prospective cohort study," PLoS One [Internet], vol. 14, no. 12, Article ID e0226683, 2019.

[4] T. A. Mega, F. B. Usamo, and G. Z. Negera, "Abacavir versus zidovudine-based regimens for treatment of HIV-infected children in resource limited settings: a retrospective cohort study," BMC Pediatr, vol. 20, no. 1, pp. 1-9, 2020.
[5] D. M. Gibb, T. Duong, P. A. Tookey et al., "Decline in mortality, AIDS, and hospital admissions in perinatally HIV-1 infected children in the United Kingdom and Ireland," $B M J$, vol. 327, no. 7422, pp. 1019-1023, 2003.

[6] D. Albrecht, M. Altfeld, G. Behrens et al., HIV Medicine [Internet], Flying Publisher, Paris, France, 2007.

[7] K. A. Gebo, J. A. Fleishman, and R. D. Moore, "Hospitalizations for metabolic conditions, opportunistic infections, and injection drug use among HIV patients," JAIDS Journal of Acquired Immune Deficiency Syndromes, vol. 40, no. 5, pp. 609-616, 2005.

[8] G. Z. Negera and T. A. Mega, "Health-related quality of life among admitted HIV/AIDS patients in selected ethiopian tertiary care Settings: a cross-sectional study," The Open Public Health Journal, vol. 12, pp. 532-540, 2019.

[9] The Antiretroviral Therapy Cohort Collaboration, "Life expectancy of individuals on combination antiretroviral therapy in high-income countries: a collaborative analysis of 14 cohort studies," Lancet, vol. 48, pp. 293-299, 2008.

[10] P. R. Teixeira, M. A. Vitoria, and J. Barcarolo, "Antiretroviral treatment in resource-poor settings: the Brazilian experience," AIDS, vol. 18, no. 3, pp. 5-7, 2004.

[11] G. Ghaffari, D. J. passalacqua, J. L. Caicedo et al., "two-year clinical and immune outcomes in human immunodefciency virus-infected children who reconstitute CD4 t cells without control of viral replication after combination antiretroviral therapy," Pediatrics, vol. 114, pp. 604-611, 2004.

[12] UNAIDS, "Regional fact sheet, sub-saharan Africa," UNAIDS, Geneva, Switzerland, 2018, https://www.unaids.org/en/regions countries/countries/ethiopia.

[13] World Health Organisation, "Antiretroviral therapy for hiv infection in infants and children: towards universal access. Recommendations for a public health approach. 2006," 2019, http://www.who.int/hiv/pub/guidelines/WHOpaediatric.pd.

[14] World Health Organization, Antiretroviral Therapy for HIV Infection in Infants and Children: Towards Universal Access 2010 Revision, World Health Organization, Geneva, Switzerland, 2019.

[15] World Health Organization, Consolidated Guidelines on the Use of Antiretroviral Drugs for Treating and Preventing HIV Infection, World Health Organization, Geneva, Switzerland, 2020.

[16] World Health Organization, "HIV diagnosis and ART use in HIV-exposed infants: A programmatic update," 2020, https:// apps.who.int/iris/bitstream/handle/10665/273155/WHO-CDSHIV-18.17-eng.pdf?ua=1.

[17] F. MoH, "Stavudine replacement strategy," 2013.

[18] C. Adjé-Touré, D. L. Hanson, N. talla-Nzussouo et al., "Virologic and immunologic response to antiretroviral therapy and predictors of HIV type 1 drug resistance in children receiving treatment in abidjan, côte d'ivoire," AIDS Research and Human Retroviruses, vol. 24, no. 7, pp. 911-917, 2008.

[19] C. Bolton-Moore, M. Mubiana-Mbewe, R. A. Cantrell et al., "Clinical outcomes and CD4 cell response in children receiving antiretroviral therapy at primary health care facilities in Zambia," JAMA, vol. 298, no. 16, pp. 1888-1899, 2007.

[20] F. rouet, P. Fassinou, A. Inwoley et al., "Long-term survival and immuno-virological response of African HIV-1-infected children to highly active antiretroviral therapy regimens," AIDS, vol. 20, no. 18, pp. 2315-2319, 2006.

[21] D. C. Wamalwa, C. Farquhar, eM. obimbo et al., "Early response to highly active antiretroviral therapy in HIV-1-infected kenyan children," JAIDS Journal of Acquired Immune Deficiency Syndromes, vol. 45, pp. 311-317, 2007. 
[22] E. Chiappini, L. Galli, P.-A. tovo et al., "Virologic, immunologic, and clinical benefits from early combined antiretroviral therapy in infants with perinatal HIV-1 infection," AIDS, vol. 20, no. 2, pp. 207-215, 2006.

[23] S. Resino, R. Resino, D. Micheloud et al., "Long-Term effects of highly active antiretroviral therapy in pretreated, vertically HIV type 1-infected children: 6 Years of follow-up," Clinical Infectious Diseases, vol. 42, no. 6, pp. 862-869, 2006.

[24] S. Biressaw, W. E. Abegaz, M. Abebe, W. A. Taye, and M. Belay, "Adherence to Antiretroviral Therapy and associated factors among HIV infected children in Ethiopia: unannounced homebased pill count versus caregivers' report," BMC Pediatrics, vol. 13, no. 1, p. 132, 2013.

[25] "National guidelines for comprehensive HIV prevention, care and treatment," pp. 1-236, 2017, https://aidsfree.usaid.gov/sites/ default/files/resources/ethiopia_art_guidelines_2017.pdf.

[26] WHO, Patient Monitoring Guidelines for HIV Care and Antretroviral Therapy ( ART ), World Health Organization, Geneva, Switzerland, 2006.

[27] V. Mulenga, V. Musiime, A. Kekitiinwa et al., "Abacavir, zidovudine, or stavudine as paediatric tablets for african HIVinfected children (CHAPAS-3): an open-label, parallel-group, randomised controlled trial," The Lancet Infectious Diseases, vol. 16, no. 2, pp. 169-179, 2016.

[28] H. Cassim, K. Otwombe, E. Lazarus et al., "A retrospective case-cohort study comparing treatment outcomes in abacavir versus stavudine containing first line antiretroviral treatment regimens in children < 3yrs old, at a paediatric programme based in Soweto, South Africa," PLoS One, vol. 12, no. 7, pp. 1-10, 2017.

[29] T. Ayele, H. Jarso, and G. Mamo, "Immunological outcomes of tenofovir versus zidovudine - based regimens among people living with HIV/AIDS : a two years retrospective cohort study," AIDS Research and Therapy, vol. 14, no. 5, pp. 1-9, 2017.

[30] Pediatric European Network for the Treatment of AIDS, "Comparison of dual nucleoside-analogue reverse-transcriptase inhibitor regimens with and without nelfinavir in children with HIV-1 who have not previously been treated: the PENTA 5 randomised trial," Lancet, vol. 359, pp. 733-740, 2002.

[31] L. Renner, M. Prin, F.-Y. Li, B. Goka, V. Northrup, and E. Paintsil, "Time to and predictors of CD4+ T-lymphocytes recovery in HIV-infected children initiating highly active antiretroviral therapy in Ghana," AIDS Research and Treatment, vol. 2011, pp. 1-9, Article ID 896040, 2011.

[32] J. M. Brenchley, T. W. Schacker, L. E. Ruff et al., "CD4+ T Cell Depletion during all stages of HIV disease occurs predominantly in the gastrointestinal tract," Journal of Experimental Medicine, vol. 200, no. 6, pp. 749-759, 2004.

[33] M. A. Luguterah, "CD4+ cell counts of HIV-1 patients on antiretroviral therapy (ART) in the builsa district hospital," European Scientific Journal, vol. 9, no. 33, pp. 299-309, 2013.

[34] R. D. Moore and J. C. Keruly, "CD4+ cell count 6 years after commencement of highly active antiretroviral therapy in persons with sustained virologic suppression," Clinical Infectious Diseases, vol. 44, no. 3, pp. 441-446, 2007.

[35] WHO, Guideline on when to Start Antiretroviral Therapy and on Preexposure Prophylaxis for HIV, World Health Organization, Geneva, Switzerland, 2018.

[36] A. Ebonyi, O. O. Agbaji, A. J. Anejo-Okopi et al., "Factors associated with a low CD4 count among HIV-1 infected patients at enrolment into HAART in jos, Nigeria," British
Journal of Medicine and Medical Research, vol. 4, no. 13, pp. 2536-2545, 2014.

[37] D. W. Gunda, S. B. Kilonzo, E. Kamugisha, and E. Z. M. B. Rauya, "Prevalence and risk factors of poor immune recovery among adult HIV patients attending care and treatment centre in northwestern tanzania following the use of highly active antiretroviral therapy: a retrospective study," BMC Research Notes, vol. 10, no. 1, p. 197, 2017.

[38] G. R. Kaufmann, M. Bloch, R. Finlayson, J. Zaunders, D. Smith, and D. A. Cooper, "The extent of HIV-1-related immunodeficiency and age predict the long-term CD4 T lymphocyte response to potent antiretroviral therapy," AIDS, vol. 16, no. 3, pp. 359-367, 2002.

[39] J. Zhou, T. Sirisanthana, S. Kiertiburanakul, Y. A. Chen, N. Han, and P. L. Lim, "Trends in CD4 counts in HIV-infected patients with HIV viral load monitoring while on combination antiretroviral treatment : results from the TREAT Asia HIV Observational Database," BMC Infectious Diseases, vol. 10, no. 1, p. 361, 2010. 